\section{A migração de enfermeiros: um problema de saúde pública}

\section{Nursing migration: a public health problem}

\section{Abstract}

This article analyzes the international scenario of nurses' migration, an essential professional class in the organization of national health systems, focusing specially on the unbalance between central and peripheral countries. It depicts studies results performed by a department of the Australian government concerning nurses, qualifying and quantifying their insertion in the labor market, as well as suggesting measures to reintegrate the nurses leaving the labor market, pointing out the reasons for the lack of nurses in developed countries. It highlights the expressive growth of nursing schools in Brazil commenting on the possible consequences of the offer of this professional in the labor market establishing a parallel with the international situation.

Key words Nursing, Migration, Labor market, Human resources in health
Thereza Christina Varella1

Célia Regina Pierantoni2
1,2 Rede Observatório de Recursos Humanos em Saúde. Instituto de Medicina Social. Universidade do Estado do Rio de Janeiro. Rua São Francisco Xavier 524, $7^{\circ}$ andar, Bloco E, sala 7010. Rio de Janeiro, RJ, Brasil. CEP: 20559-900. Tel: 21 - 2234-7378. E-mailvarella@ims.uerj.br

\section{Resumo}

$O$ artigo analisa o cenário internacional de migração do enfermeiro, uma das categorias em destaque na constituição de sistemas nacionais de saúde, apontando especialmente o desequilíbrio entre países centrais e periféricos. Apresenta os resultados de estudos realizados por um órgão do governo australiano realizado junto aos enfermeiros, qualificando e quantificando a inserção deste profissional no mercado de trabalho, bem como apontando medidas para motivar reintegração dos enfermeiros que evadiram do mercado de trabalho. Destaca o crescimento expressivo de cursos de enfermagem no Brasil, traçando considerações sobre os possíveis desdobramentos da oferta desse profissional, estabelecendo um paralelo com o cenário internacional.

Palavras-chave Enfermeiro, Migração, Mercado de trabalho, Recursos humanos em saúde 


\section{Introdução}

\section{O trabalho no mundo globalizado}

A partir da Segunda Guerra Mundial, o mundo vem sofrendo uma reestruturação econômica, desencadeada pelo sistema capitalista, que resultou em internacionalização dos mercados, quebra de barreiras econômicas e culturais, com sofisticação do mercado financeiro, da oferta de bens e de produtos e extraordinário desenvolvimento da indústria de informação. Tais mudanças, acentuadas nas últimas décadas, tiveram repercussão nas formas de organização do Estado e na estrutura produtiva. ${ }^{1}$

Observa-se, em paralelo, uma sensível mudança no mundo do trabalho, com reflexos significativos na organização societária e deslocamento da centralidade do trabalho como estruturante da sociabilidade humana. O sentido do trabalho precisa ser (re)significado em sua forma contemporânea, enquanto trabalho social que se complexifica e intensifica ritmos e processos. A sociedade do capital necessita cada vez menos do trabalho estável e se utiliza cada vez mais de formas diversificadas. ${ }^{2}$

O padrão de acumulação capitalista, baseado nos moldes taylorista - fordista de produção massificada, cede lugar às formas produtivas flexibilizadas, desregulamentadas, vinculadas a novos patamares de demanda por produtos especializados. A demanda do mercado por produtos versáteis e de qualidade, um dos pontos centrais de inflexão do fordismo, reorganizou a estrutura produtiva, configurando-se o novo paradigma da especialização flexível, que veio contrapor a economia de escala à economia de escopo, baseada na encomenda do produto.

Teoricamente, se por um lado a modernização produtiva teria em seu bojo pontos ditos favoráveis, tais como aumento da participação e qualificação do trabalhador (o trabalho polivalente), por outro, o que se observa no caso brasileiro, é muito mais uma precarização do emprego, downsizing (enxugamento dos efetivos) e terceirização.

Entram ainda neste cenário as políticas centradas em processos de reforma, com as proposições relacionadas com "diminuição" do Estado, perda da proteção social do trabalho e dos trabalhadores, globalização financeira com hegemonia do capital financeiro sobre o capital produtivo, agravando a situação de empregabilidade.

Cada vez mais, no perfil dos trabalhadores, são exigidas novas características, que transformam radicalmente a forma de se conceber a formação para o trabalho em sua concepção institucional, em suas formas de detecção de necessidades e na estruturação de seus programas formativos.

É consensual que as modificações do mundo do trabalho vêm requerendo novos atributos profissionais: criatividade e autonomia na busca do conhecimento; capacidade de liderança para negociar conflitos em trabalhos realizados em grupo; competências para desenvolver quadros teóricos, analíticos e críticos, que lhes permitam acompanhar o desenvolvimento do conhecimento e as demandas de reconversão profissional. ${ }^{3}$

No plano social, as repercussões para os trabalhadores das escolhas demandadas pela chamada "nova economia" e seus produtos e processos envolvem um contínuo de insegurança quanto ao mercado, ao emprego, à renda, à contratação, à competências e à representação do próprio trabalho, entre outras. O modelo de "trabalho" deixa de assumir importância de ocupação, de ofício, de profissão, e, mais ainda de dado de identidade social, que estimulava solidariedades e conflitos, lutas e negociações, vitórias e derrotas.

A quebra de barreiras no mundo globalizado também reconfigurou o fluxo de trabalhadores de saúde. A migração da força de trabalho em saúde se intensifica, alcançando patamares que tornam a situação crítica para países periféricos. A formação de capital intelectual de uma nação deve se constituir em uma das preocupações básicas de todo o governo. A formação de recursos humanos em saúde, em especial, tem embutido um alto custo para sociedade, especialmente em países em desenvolvimento e vem sendo objeto de discussão na agenda global para essa área.

Destacaremos, neste artigo, particularmente a situação dos enfermeiros, categoria crítica na constituição dos sistemas nacionais de saúde, cuja escassez, em várias partes do mundo, desencadeia intenso desequilíbrio entre países centrais e periféricos.

\section{O trabalho do enfermeiro no cenário internacional: a migração em destaque}

Contrariando o ufanismo de melhoria na repartição das riquezas e de um mundo mais homogêneo, a globalização econômica acirrou a assimetria entre os países, elevando os patamares de pobreza de um conjunto majoritário de nações, que concentram dois terços da população mundial.

Essa globalização contornou uma nova divisão internacional do trabalho, estabelecendo uma concorrência desleal entre países centrais, semiperiféricos e periféricos. ${ }^{4}$ As forças do mercado não 
operam no sentido da igualdade, mas por estímulo a padrões concorrenciais de eficiência definidos pela racionalidade do modelo econômico capitalista. Este movimento reforça uma disponibilidade de postos de trabalho menos qualificados e mais mal remunerados nos países pobres. 4

O planejamento e o gerenciamento dos recursos humanos da saúde configuram-se pontos nodais para o equacionamento dos profundos problemas associados à pobreza de um número crescente de países com alto grau de endividamento e com baixa capacidade institucional, particularmente para implementação da política setorial.

O cenário internacional aponta uma série de desafios no que se refere às questões de RH. Alguns já se acumulam ao longo dos anos, com destaque para a baixa remuneração e motivação das equipes de saúde, para a iniqüidade distributiva da força de trabalho, e para o desempenho e accountability insatisfatórios dos profissionais. Somam-se também desafios emergentes, como a migração entre países, baixa capacidade de preparação e fixação de recursos humanos e o impacto da epidemia do HIV/AIDS na força de trabalho da saúde, 5 resultando em absenteísmo e sobrecarga de trabalho. 6

O relatório da Joint Learning Initiative (JLI) sobre recursos humanos em saúde no mundo cita, além das questões já referidas (a devastação pela AIDS e a migração entre países), o legado de um baixo investimento crônico em recursos humanos. Tal legado pode ser traduzido, em duas décadas de diminuição de despesas com reformas econômica e setorial, por congelamento de salários e paralisação do recrutamento de pessoal, baixo investimento público e toda a sorte de diminuição das condições de trabalho por falta de suprimentos e medicamentos básicos e outras retrações de facilidades inerentes ao trabalho em saúde. ${ }^{7}$

O estudo empírico desenvolvido pela JLI aponta uma estreita relação entre a concentração de recursos humanos e os níveis de mortalidade e de expectativa de vida. O estudo tomou as Metas de Desenvolvimento do Milênio (cobertura vacinal por sarampo e assistência ao nascimento) e estabeleceu que uma densidade de 2,5 trabalhadores de saúde por 1000 habitantes pode ser considerada um limite mínimo necessário para atingir a cobertura adequada. Estima-se que 75 países no mundo, que concentram 2,5 bilhões de pessoas, estão abaixo desse mínimo. ${ }^{7}$

A Enfermagem é uma categoria profissional crítica, especialmente nos países periféricos e subdesenvolvidos. Tal situação vem se agravando, tanto no que se refere a elementos quantitativos (em geral, uma situação deficitária ou com tendência decres- cente da disponibilidade de pessoal), como a elementos qualitativos referidos ao desenvolvimento de competências laborais, oportunidades de qualificação para o exercício profissional e as deficientes condições de trabalho, entre outras características.

De acordo com o Conselho Internacional de Enfermagem (CIE), o panorama é marcado pela falta de enfermeiros e por desequilíbrios na sua distribuição entre as várias regiões do globo e, em certos casos, pela sub-utilização dos profissionais disponíveis.

Os processos históricos de profissionalização da categoria são diferentes entre os diversos países, alcançando, em alguns, um significativo grau de autonomia e valorização social, ao passo que em outros apresentam reduzido status técnico e reconhecimento econômico e social. Ademais, o grau de qualificação para o exercício profissional também é diversificado, variando de um país para outro, com reconhecimento de categorias de nível médio de escolarização e de nível superior.

$\mathrm{Na}$ atualidade, a enfermagem tem ocupado posição de destaque na agenda internacional, dada a redução dos efetivos em países centrais, particularmente no Canadá, Reino Unido e Estados Unidos. ${ }^{8}$ As deficiências desses países vêm sendo supridas cada vez mais com profissionais do mundo em desenvolvimento.

Organizações de enfermagem de 69 países, geograficamente dispersos por todo o mundo, reportaram falta de enfermeiros e 33 países da Oceania, África, e América Central assinalam como preocupante ou extremamente preocupante a emigração de enfermeiros em direção a países mais ricos segundo dados da Ordem dos Enfermeiros de Portugal no ano de 2003.

A migração internacional não é um fenômeno recente, já sendo relatado no final do século XIX e início do século $\mathrm{XX}$, em que europeus buscavam melhores condições de trabalho na América, e em meados do século passado, fugindo da guerra e de suas conseqüências. Entretanto, esse fenômeno se torna mais crescente e complexo com a internacionalização da economia. 9

$\mathrm{O}$ processo migratório de recursos humanos em saúde já vinha sendo relatado na década de 90 . A Divisão de Recursos Humanos da Organização Panamericana da Saúde (OPAS) na Argentina, apontou, em 1991, que cerca de 2000 enfermeiros, em três anos, haviam abandonado o país atraídos pela oferta de melhores salários em outros países - entre eles, Estados Unidos, Espanha, Itália e Austrália.10

As correntes migratórias, entretanto, não ocorrem tão somente de países em desenvolvimento 
para países centrais, mas tendem também de zonas rurais para centros urbanos. A oferta de postos de trabalho mais atrativos e mais bem remunerados tem sido apontada como elemento especialmente motivador destes movimentos. O baixo desenvolvimento econômico, as deficiências nas condições de vida e as poucas oportunidades de desenvolvimento profissional são elementos que se agregam como causa da evasão dos profissionais de países e áreas de pouco desenvolvimento.

Portes ${ }^{11}$ categoriza em três níveis os fatores determinantes de processos migratórios: no nível primário ou internacional, no secundário ou estrutural interno e no terciário ou individual. De acordo com esse autor, situam-se no nível primário aqueles relacionados às diferenças socioeconômicas entre os países desenvolvidos e subdesenvolvidos, e podem ser observados pelas vantagens oferecidas pelos primeiros no que diz respeito ao acesso a melhores oportunidades salariais e de condições de vida. Os fatores secundários estão determinados pelo desequilíbrio nos países de origem dos migrantes entre a oferta de profissionais e a capacidade de absorção pelo sistema de saúde local, o que não significa necessariamente um superávit de recursos humanos qualificados, mas aponta, também, para as limitações dos sistemas produtivos para empregá-los. Constituem os fatores do terceiro nível ou individual aqueles ligados à idade, ao estado civil, às responsabilidades familiares e às oportunidades de desenvolvimento profissional e de remunerações atraentes.

Os fatores que influenciam os movimentos migratórios estão fora do controle dos responsáveis pelas políticas do setor saúde. É consensual que os fatores ligados às perspectivas de emprego se constituem como uma das questões centrais que influenciam os profissionais de saúde na tomada de decisão em relação à migração. Neste sentido, a opção mais usual para fixação de profissionais em países fornecedores de mão-de-obra se baseia em políticas de elevação dos níveis salariais. Entretanto, não há evidências sobre a probabilidade de sucesso dessas iniciativas, em função da complexidade dos determinantes destes processos.

O fato é que as diferenças salariais observadas entre os países "exportadores" e os "receptores" apresentam variações significativas. O salário pago aos enfermeiros na Austrália e no Canadá é cerca de 25 vezes maior ao de Zâmbia, 14 vezes maior que o de Gana e o dobro do verificado na África do Sul.12

Ao se considerar a migração internacional, além de questões situadas no campo dos direitos (trabalhistas e humanos) dos profissionais que emigram de seus países, deve-se ter em conta como preocupação coletiva a saúde da população dos países exportadores de mão-de-obra. O fluxo de saída de profissionais de saúde pode afetar de forma adversa o sistema de saúde e, conseqüentemente, a saúde da população.

A emigração de profissionais de saúde dos países em desenvolvimento tem se tornado, cada vez mais, um problema que assume dimensões alarmantes, uma vez que, por um lado, esses países já contam com estoques reduzidos de profissionais e, por outro, detêm baixa capacidade institucional para promover a preparação de efetivos que possam suprir as demandas domésticas. Casos exemplares podem ser observados: o Zimbabwe, em 2001, registrou a saída do equivalente a $64,2 \%$ dos graduados naquele ano, só para o Reino Unido (não existem registros de quantos migraram para outros países), enquanto esta proporção foi 5,2\% em 1997; nas Filipinas, no ano de 1996, cerca de 4500 enfermeiros deixaram o país, e em 2001 este quantitativo triplicou. Por outra via, no ano de 2002, dos 16.000 novos registros de enfermeiros no Reino Unido, mais de $50 \%$ eram de estrangeiros. 12

Agências privadas de recrutamento de recursos humanos em saúde, que cobram honorários pelos seus serviços, vêm intervindo nas migrações internacionais, utilizando-se, em muitas das vezes, de dispositivos éticos duvidosos. No Brasil já existem agências oferecendo 126 mil vagas de trabalho para enfermeiros nos EUA. Tais agências estão oferecendo cursos preparatórios para enfermeiros e estudantes de enfermagem de quinto período e garantem salários de até US\$ 40.000,00 anual e Greencard extensivo à família. A preocupação com a migração internacional tem levado grupos como a Commonwealth Secretariat 13 a desenvolver movimentos que promovam práticas éticas para o recrutamento internacional.

Os países fronteiriços, e com acordos de livre comércio e de serviço, também têm vivenciado o fluxo migratório. Os enfermeiros espanhóis estão buscando oportunidades de trabalho em Portugal. A principal explicação para esse fluxo é o mercado de trabalho, que se apresenta com restrição de postos de trabalho na Espanha, e a baixa oferta de enfermeiros e a demanda no mercado de trabalho em Portugal. Outras condições também influenciam o movimento migratório, como as geopolíticas, culturais e lingüísticas, bem como a equivalência no nível de formação e ensino nos dois países.

Como nas demais situações relatadas, a imigração de enfermeiros espanhóis em Portugal se mostrou mais acentuada a partir de 2000 , onde foram 
registrados 350 enfermeiros espanhóis. O fluxo intensificou-se rapidamente passando para $740 \mathrm{em}$ 2001 e 1537 em 2002, quase que duplicando a cada ano. O ano de 2003 terminou, segundo dados de 2004 da Ordem dos Enfermeiros de Portugal, com 1801 registros de enfermeiros espanhóis no país. ${ }^{14,15}$

Estudos realizados em Portugal mostram que os enfermeiros espanhóis que ali estão são jovens, predominando a faixa etária abaixo dos 30 anos $(85,5 \%)$; majoritariamente do gênero feminino $(69,9 \%)$ e buscam as instituições portuguesas como acesso ao primeiro emprego e para adquirir experiência profissional. ${ }^{14,15}$

$\mathrm{Na}$ América do Sul, com o aprofundamento das relações de livre comércio e de serviço dos países do MERCOSUL, o fluxo migratório entre países deverá ser intensificado e demandará estudos e acordos, tanto no que diz respeito aos impactos nos mercados de trabalho nacionais, como no estabelecimento de compatibilização dos níveis educacionais e de formação entre países. Ademais, não se dispõe de informações atualizadas 9 dos outros países, o que deixa uma série de questões ainda em aberto.

Dados apresentados em documento produzido pela OPAS 16 mostram que mais de 100 enfermeiros da Costa Rica emigraram para os Estados Unidos nos últimos anos; Honduras refere mais de 50 enfermeiras emigrando para outros países; na Nicarágua mais de 150 enfermeiros saíram do país, sendo 87 no ano de 2004; mais de 2000 enfermeiras deixaram o Panamá na década de 80 e o mesmo número saiu de Porto Rico em 2003 para buscar trabalho nos EUA. Cuba apresenta uma situação peculiar, pois tem 528 enfermeiros em outros 34 países, mas em programas de cooperação técnica internacional. Outros países da América referem migração de enfermeiros, mas as informações são dispersas e não estão sistematizadas. 17

O estudo de fluxos migratórios, no cenário internacional, para a análise dos impactos decorrentes da emigração e da imigração de profissionais de saúde nos diversos países envolvidos, exige o desenvolvimento de estratégias para o registro e disponibilização de informações sobre recursos humanos em saúde. Tais informações se encontram dispersas e dependem da capacidade institucional setorial dos diferentes países, que apresentam grau de variação e de vulnerabilidade bastante diverso. ${ }^{8}$

O relatório encomendado pela International Council of Nurses, em 2005, aponta como recomendações para o desenvolvimento de soluções sustentáveis para os problemas decorrentes da migração internacional de enfermeiros: 8

- Dados precisos dos fluxos internacionais de migração de enfermeiros. A ausência de tais dados é uma lacuna crucial; este é um constrangimento em qualquer processo de monitoramento efetivo, e também um limitante para que se desenvolva expertise para avaliação de impacto. Stakeholders, em nível nacional, e agências internacionais necessitam estabelecer acordos de colaboração para desenvolvimento de instrumentos para melhorar o sistema de monitoramento do fluxo internacional de enfermeiros e de outros trabalhadores de saúde.

- A posição de muitos países em desenvolvimento, que são fontes internacionais de trabalhadores de enfermagem, é debilitada por dados de mão-de-obra inadequados e baixa capacidade de planejamento. Há dificuldade de avaliar o quanto é "problema" o fluxo para outros países em comparação ao número de enfermeiros subempregados e desempregados dentro do país. Esses países têm que avaliar tais questões e melhorar seus sistemas de planejamento, dando mais atenção a políticas para encorajar e apoiar os que estão fora do mercado a retornarem ao trabalho.

- O impacto global da saída de enfermeiras dos países fonte, seja em termos de seu efeito na organização do sistema de saúde, seja na implicação com o restante do pessoal, requer avaliação mais sistemática. Para isso fazem-se necessárias mais pesquisas de avaliação para informar stakeholders nacionais e agências internacionais do verdadeiro impacto e custo (e/ou benefícios) da migração de enfermeiros.

- Relativamente pouco se sabe sobre as experiências de enfermeiros migrantes que trabalham agora nos países de destino, em termos de seu perfil e carreira futura planejada (inclusive probabilidade de retorno para países de origem ou possibilidade de movimento para outros países), e seu tratamento em relação aos enfermeiros locais. São requeridas estruturas e serviços para proteger enfermeiros migrantes de exploração e de abuso, promovendo seu bemestar geral e sua integração, bem como identificando suas necessidades. Pesquisas e avaliações são requeridas para destacar boas práticas e desencorajar práticas indesejáveis no tratamento de enfermeiros migrantes.

- As questões de gênero em relação à migração de enfermeiros são consideradas como um fator importante; há necessidade de que os países doadores apóiem e fortaleçam associações/organizações profissionais de enfermagem nos países de origem, de forma que a posição da enfermagem possa ser promovida através de uma advocacia mais forte.

- Faz-se relevante às questões de "como" ou "se" 
"administra" a migração, remetendo para investigações mais sistemáticas, que estabeleçam modelos de migração administrada. As várias políticas e modelos de migração administrada (acordo bilateral, códigos éticos, esquemas de retorno de migrantes e possíveis modelos de "treinando para exportação") exigem exame e avaliação, de forma a apoiar uma aproximação mais efetiva entre recrutamento internacional e o nível nacional e internacional de enfermagem aceitável.

A tentativa de apontar vantagens e desvantagens da migração teria, necessariamente, que ser equilibrada entre o enfoque do profissional que busca melhores condições de emprego, trabalho e condições vida, e o ponto de vista dos países fontes e recebedores. Os países que sofrem com a emigração, enfrentam a desestruturação de seus sistemas de saúde, com a fuga de cérebros e perdas dos investimentos financeiros no desenvolvimento de recursos humanos. Para os recebedores, a perspectiva de utilizar mão-de-obra estrangeira soluciona o déficit local. Tais países, com base econômica mais sólida, representam melhores perspectivas de vida e de trabalho para profissionais com poucas alternativas em seus países de origem.

\section{O trabalho dos enfermeiros na Austrália:} alguns aspectos de um país receptor de enfermeiros

A escolha da Austrália se deu pela possibilidade de visita ao país. Os dados foram obtidos em visita ao órgão responsável pelo registro dos profissionais de saúde.

De acordo com o New South Wales (NSW), Health Department Nursing and Midwifery Office, 18 a Austrália conta com cerca de 100 mil enfermeiros. Em NSW, a força de trabalho de enfermagem constitui-se como um dos maiores contingentes de trabalhadores do sistema de saúde, com aproximadamente 40.000 enfermeiros empregados apenas no sistema público de saúde. Junto com os enfermeiros empregados nos setores Privado, Comunitário e de Cuidado a Idosos, constituem o maior percentual da força de trabalho dos serviços de saúde e da comunidade. A enfermagem presta serviços accessíveis 24 horas por dia, durante todo o ano. O recrutamento e a fixação de enfermeiros continuam a ser uma grande prioridade do Governo do NSW, que atualmente, vem adotando estratégias com essas finalidades. Os enfermeiros, como todos os demais trabalhadores, são influenciados pelas escolhas de estilo de vida e vêm demandando mais acesso a turnos de trabalho parcial, para que possam equilibrar suas vidas entre a família, estudo e outras atividades sociais. Isso se constitui em significativos desafios para os gestores do sistema de saúde, que são exigidos a providenciar equipes para prover os serviços de saúde nas 24 horas do dia e em toda a semana. ${ }^{19}$

Reconhece-se, também, que várias das questões que impactam no recrutamento e na fixação são de natureza social e não específicas da força de trabalho. A maioria dos enfermeiros é do sexo feminino, muitas das quais se afastam do mercado de trabalho em saúde por períodos variáveis, para criar seus filhos e gerir outras responsabilidades familiares. A qualificação dos enfermeiros oferece mobilidade (tanto interestadual quanto internacionalmente) facilitando viagens e afetando o fluxo de trabalhadores no mercado. A Austrália é um país carente de mão-de-obra em todas as áreas, acarretando, assim, uma crescente "competição" entre muitas ocupações no recrutamento de recém-graduados e pós-graduados em enfermagem, que verificam que sua qualificação oferece outras oportunidades de trabalho fora da enfermagem. Todos os outros Estados australianos vêm encarando questões similares relativas à sua força de trabalho em enfermagem, bem como muitos sistemas de saúde internacionais. O desafio é como enfrentar tais questões de forma a atrair os enfermeiros para continuarem dando sua contribuição profissional para o sistema de saúde. 19

Estudos realizados $18,19 \mathrm{em} 2000$ sobre a força de trabalho de enfermagem, mostram que NSW conta com 57.035 enfermeiros. A enfermagem na Austrália é constituída por três categorias de profissionais: as Enrolled Nurse (EN) com formação técnica de um ano; as Registred Nurse (RN) com formação universitária de três anos e Midwives, com especialização em obstetrícia, e concentram parte expressiva das enfermeiras que trabalham na Austrália. As RN representam $82,9 \%$ deste contingente. Nos dois grupamentos são predominantes os profissionais do sexo feminino, $91,25 \%$, e $55,8 \%$ estão na faixa de 20 a 44 anos. Tal estudo aponta uma tendência ao envelhecimento da força de trabalho.

No emprego considerado principal, $74,4 \%$ das enfermeiras trabalham no setor público e $82,9 \%$ em emprego permanente. Já quando investigado sobre o segundo emprego, $51,3 \%$ estão no setor privado e $80,8 \%$ referiram o segundo emprego como temporário ou casual. Cabe ressaltar que apenas $10,5 \%$ dos enfermeiros pesquisados declaram um segundo emprego. Em relação à localização geográfica, 73,5\% trabalham em áreas metropolitanas e $25,6 \%$ nas áreas rurais. Este percentual se modifica 
um pouco no segundo emprego, aumentando a concentração nas áreas metropolitanas $(76,7 \%)$.

De acordo com a pesquisa, as áreas de atividade dos trabalhadores de enfermagem se mostram assim distribuídas: $36,7 \%$ trabalham em clínica médica; 17,1\% em clínica cirúrgica e cirurgia; 5,8\% em mix médico-cirúrgica; $1,8 \%$ em meios diagnósticos; $9,0 \%$ em emergência e cuidados críticos; $6,8 \%$ em saúde mental; 7,8\% em obstetrícia; $14,9 \%$ em outras áreas. Neste último grupo observa-se que 3,2\% trabalham com enfermagem geral e comunitária e $0,1 \%$ em serviços de saúde aborígine. Essa distribuição praticamente não se altera quando considerado o segundo emprego.

Em relação ao número de horas trabalhadas por semana no emprego principal, destacamos que $24,1 \%$ situam-se na faixa de 35 a 39 horas semanais; $23,7 \%$ na de 40 a 44 horas por semana e $22,5 \%$ entre 20 e 29 horas na semana. Já no segundo emprego, $53,9 \%$ trabalham até nove horas e 33,6\% de 10 a 19 horas semanais.

O estudo identificou o país de nascimento das RN e observou-se que $25 \%$ são estrangeiros oriundos principalmente do Reino Unido $(8,6 \%)$ e da Ásia (8,1\%). Já entre as EN, 82,5\% são de origem australiana, e o maior percentual de estrangeiros é originário do Reino Unido.

Os dados apresentados sobre a classificação do principal emprego das $\mathrm{RN}$ mostram que a maioria trabalha como enfermeiro clínico e que apenas $2,6 \%$ trabalham na educação e $0,5 \%$ em pesquisa.

Outro estudo, desenvolvido pelo NSW18 sobre a estrutura dos serviços de obstetrícia, aponta uma falta de informação sobre as enfermeiras parteiras (midwives), pois não existem dados disponíveis, o que dificulta o desenvolvimento de metodologias de planejamento. Entretanto, as informações disponíveis mostram uma baixa provisão de parteiras qualificadas para uma alta demanda de postos de trabalho que efetivam constantemente o recrutamento. Esse problema foi identificado em nível nacional, e em particular no Estado de NSW.

De fato, o país vem desenvolvendo mecanismos de reintegração à força de trabalho em saúde de um quantitativo expressivo de enfermeiros com qualificação, que saíram do mercado de trabalho. Dados de 1998 apontam que cerca de 35 mil enfermeiros mantêm seus registros ativos, mas não desempenham atividades nos serviços de saúde.

Foram feitas pesquisas em $2000,18,19$ por levantamento postal, com 31.117 enfermeiros identificados na época como não exercendo atividades de enfermagem. Foram também realizadas entrevistas telefônicas para enriquecer os dados do levanta- mento. Das 10.089 respostas, um total de 3253 enfermeiros indicou que poderiam considerar a possibilidade de retorno à enfermagem. O perfil desses 3253 enfermeiros incluiu: faixa etária de 34 a 45 anos (média de 40 anos); especialidades preferidas: cirurgia, trabalho de parteira (midwifery) e cuidados críticos; $50 \%$ têm filhos com menos de 12 anos de idade; $63 \%$ querem trabalhar apenas de segunda a sexta-feira, sem trabalho em turnos. Os motivos mais comumente citados pelos enfermeiros que participaram da pesquisa para não trabalharem em enfermagem no NSW incluem: responsabilidades familiares; necessidade de trabalho em turnos; necessidade de re-treinamento; escolhas de estilo de vida; razões de saúde/lesões ocupacionais. Isso nos mostra que os enfermeiros consideram com seriedade a dualidade de suas responsabilidades entre família e carreira, e que eles querem acesso ao aprofundamento de sua educação profissional. Apontam também que parte significativa do trabalho que exercem demanda esforços físicos, o que tem implicações sobre sua própria saúde e bem-estar.

O fato é que na Austrália, um país de pleno emprego, a dificuldade de fixar a mão-de-obra de enfermagem é maior, e os governantes vêm buscando adotar medidas que sejam atrativas para este conjunto de profissionais.

\section{O boom da graduação de enfermagem no} Brasil. O país poderá exportar enfermeiros?

Atualmente, ao enfermeiro, como em outras profissões da saúde, é exigido concluir um curso de graduação para ser considerado apto para o exercício profissional. Assim, apresentaremos alguns aspectos do mercado educativo, as principais tendências das últimas décadas, estabelecendo um paralelo com a dinâmica internacional.

A primeira iniciativa de que se tem registro sobre os dados em nível nacional da enfermagem, deve-se à Associação Brasileira de Enfermagem (ABEn), que realizou entre 1956 e 1958 um levantamento de Recursos e Necessidades de Enfermagem no Brasil, para atender a uma demanda da Fundação Kellogg, que solicitava informações das escolas de enfermagem do país, bem como de alunos matriculados e diplomados, dentre outras questões. 20 Tem-se registro de um estudo publicado pela ABEn em 1969 sobre a formação de Pessoal de Enfermagem no Brasil. Em 1975, o Ministério da Educação e Cultura (MEC) divulgou um trabalho intitulado "Desenvolvimento do Ensino Superior de Enfermagem". Na década de 80, o Conselho Federal 
de Enfermagem (COFEN) e a ABEn realizaram uma pesquisa de campo, publicada em 1985, retratando o Perfil da Força de Trabalho de Enfermagem. ${ }^{21}$

O resultado deste levantamento apontou que, já naquela época, havia uma proliferação desordenada de escolas, sem considerar as necessidades regionais, além de ausência de um órgão controlador e fiscalizador das escolas; de um número reduzido de candidatos para os cursos existentes; de um corpo docente deficiente em quantidade e em qualidade e, por fim, da grande diversidade de currículos de um curso para outro. 22

A tendência expansionista de cursos e instituições do ensino de enfermagem é percebida a partir da década de 70. O crescimento de escolas era a solução, apontada pelas entidades de enfermagem, para suprir o déficit de enfermeiros no país. Somado a isso havia uma política governamental de expansão de vagas e de acesso da classe média ao ensino superior. Entre 1970 e 1985 houve um crescimento de $210 \%$ no quantitativo de instituições de graduação de enfermagem. Em 1990, o número de escolas era

\section{Figura 1}

Instituições de graduação de enfermagem. Brasil, 1970 a 2001.

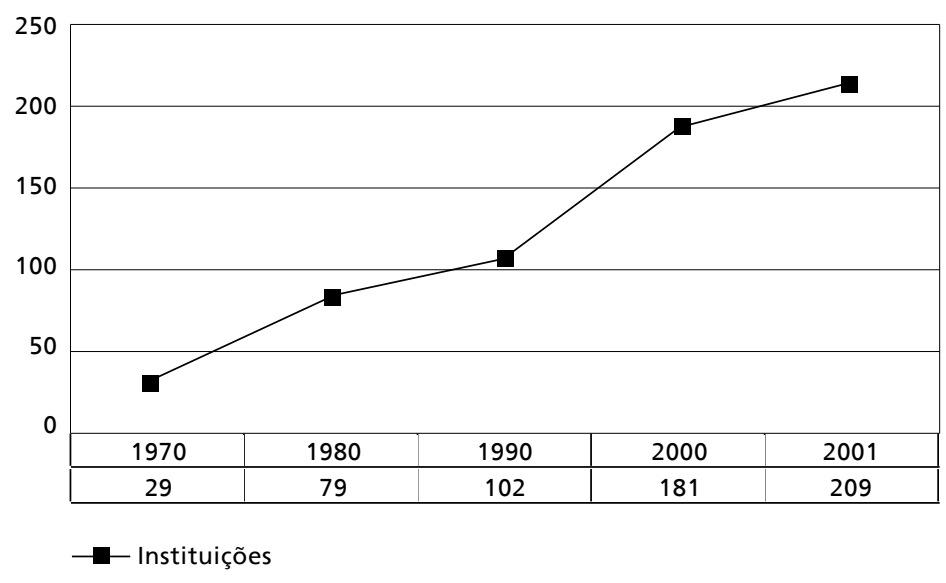

Fonte: Instituto Nacional de Estudos e Pesquisas Educacionais Anísio Teixeira (INEP), Ministério da Educação, Observatório de Recursos Humanos em Saúde (OBSRHS), Instituto de Medicina Social (IMS), Universidade do Estado do Rio de Janeiro.

de 102, alcançando 181 em $2000^{23}$ (Figura 1).

Observa-se, entretanto, que o crescimento de instituições de graduação de enfermagem, além de não se manter constante, não teve correspondência na procura por vagas nos cursos, no número de egressos no decorrer da década de 70 e 80, nem tampouco na configuração da estrutura ocupacional da enfermagem.

A década de 70, quando se alavanca o desenvolvimento do setor médico assistencial privado, deixa como herança para a área de enfermagem uma polarização na assistência entre médicos e atendentes, e um déficit de enfermeiros e auxiliares de enfermagem. Se, em 1956, os enfermeiros representam $11,3 \%$ da força de trabalho em enfermagem, no início da década de 80 este percentual decresce para $8,5 \% .24$

$\mathrm{O}$ acesso de estudantes à universidade, nos anos 80 , comporta-se com um afunilamento crescente, mostrado pelo aumento da relação candidato/vaga em carreiras como medicina e odontologia. $\mathrm{Na}$ enfermagem, ao contrário, essa relação sofre uma redução e estabilização de candidatos para os cursos da área. Algumas análises pouco otimistas apontavam para o risco de extinção da profissão, explicado, por um lado, pela pouca procura e, por outro, pela expressiva evasão. 25

A situação de baixa procura pelos cursos de enfermagem, embora se observasse uma grande empregabilidade nas instituições/serviços de saúde, pode ser vista por situações exemplares: a Escola Paulista de Medicina (hoje denominada Universidade Federal de São Paulo - UNIFESP), em 1988 reduziu suas vagas de 120 para 80; a Escola de Enfermagem da Universidade de São Paulo, também em 1988, preencheu apenas 33 vagas das 80 oferecidas, da mesma forma que a Escola de Enfermagem de Ribeirão Preto, da mesma Universidade, teve apenas 12 vagas preenchidas em 1986 e 33 em 1987. A Universidade do Oeste Paulista (UNIOESTE) não realizou o concurso vestibular para enfermagem em 1988 por falta de candidatos. Ainda no mesmo ano, a Escola de Enfermagem Anna Nery, no primeiro semestre, preencheu apenas seis vagas das 60 oferecidas. 26

Por outra via, o número de egressos de graduação de enfermagem em 1980 era de 3139, e em 83 chega a 4934, quando se inicia um declínio acentuado, alcançando em 1990 um quantitativo de 3359 diplomados (Figura 2).

A década de 90 registrou um aquecimento no sistema educativo da enfermagem, com uma expressiva expansão de cursos e de vagas para a graduação em enfermagem. Note-se que, na primeira metade dessa década, predominavam cursos de instituições públicas, sendo este percentual em 1991 de 57,5\%. Este quadro começa a se inverter em 2000, onde $59,01 \%$ dos cursos são oferecidos em instituições de natureza privada.

O aumento do número de vagas neste período foi atrelado à expansão do setor privado. Em 1991, 
Egressos da graduação de enfermagem. Brasil, 1980 a 1990.

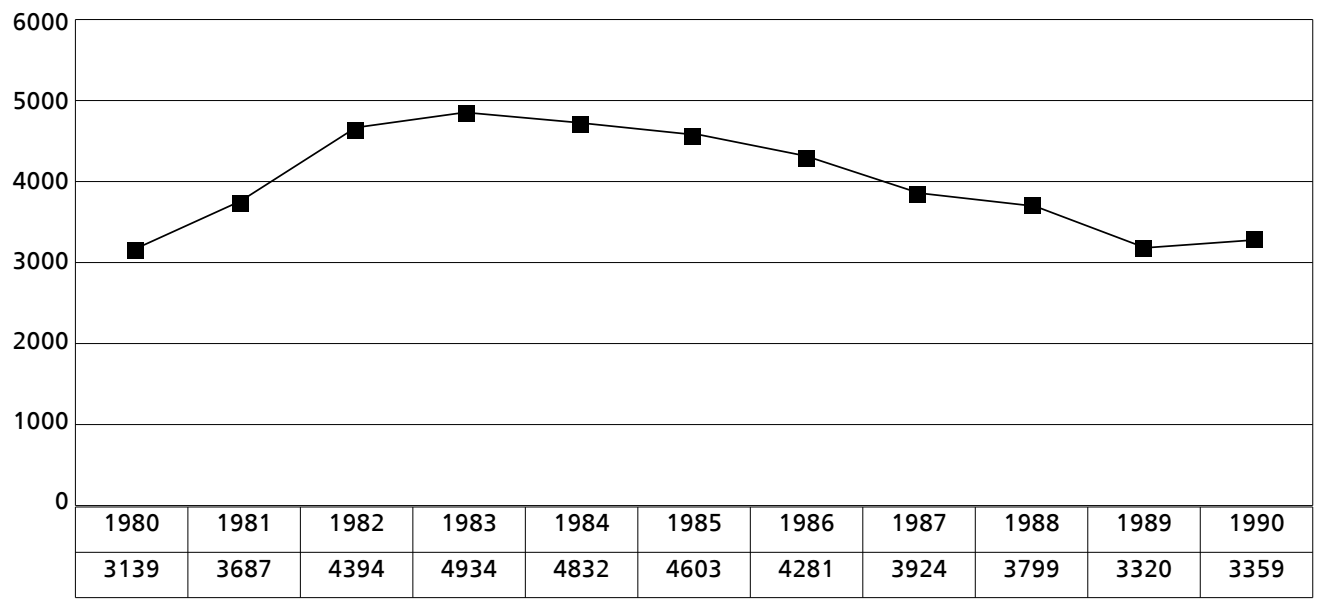

- Instituições

Fonte: Instituto Nacional de Estudos e Pesquisas Educacionais Anísio Teixeira (INEP), Ministério da Educação,

Observatório de Recursos Humanos em Saúde (OBSRHS), Instituto de Medicina Social (IMS), Universidade do Estado do Rio de Janeiro.

Figura 3

Vagas de graduação de enfermagem segundo natureza administrativa. Brasil, 1991 a 2004.

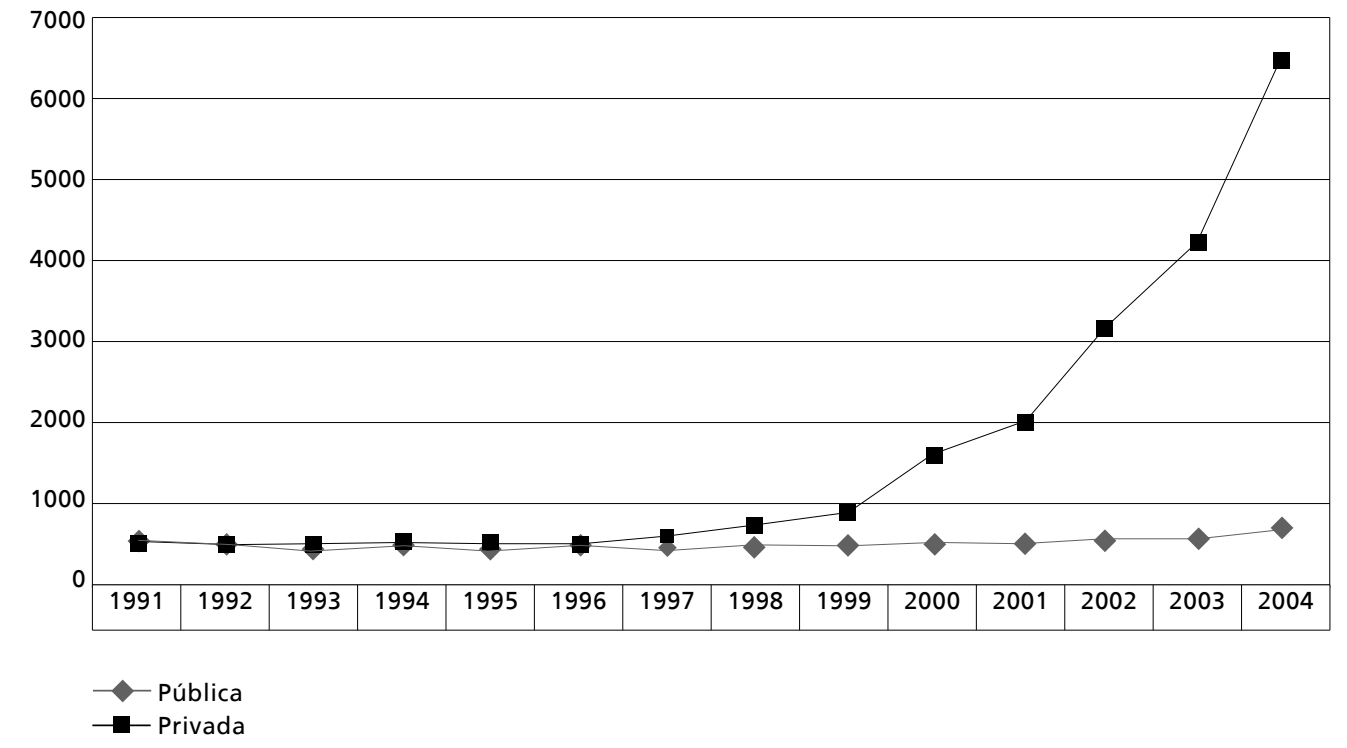

Fonte: Instituto Nacional de Estudos e Pesquisas Educacionais Anísio Teixeira (INEP), Ministério da Educação,

Observatório de Recursos Humanos em Saúde (OBSRHS), Instituto de Medicina Social (IMS), Universidade do Estado do Rio de Janeiro. 
Evolução do percentual de ocupação das vagas de graduação de enfermagem. Brasil, 1991 a 2004.

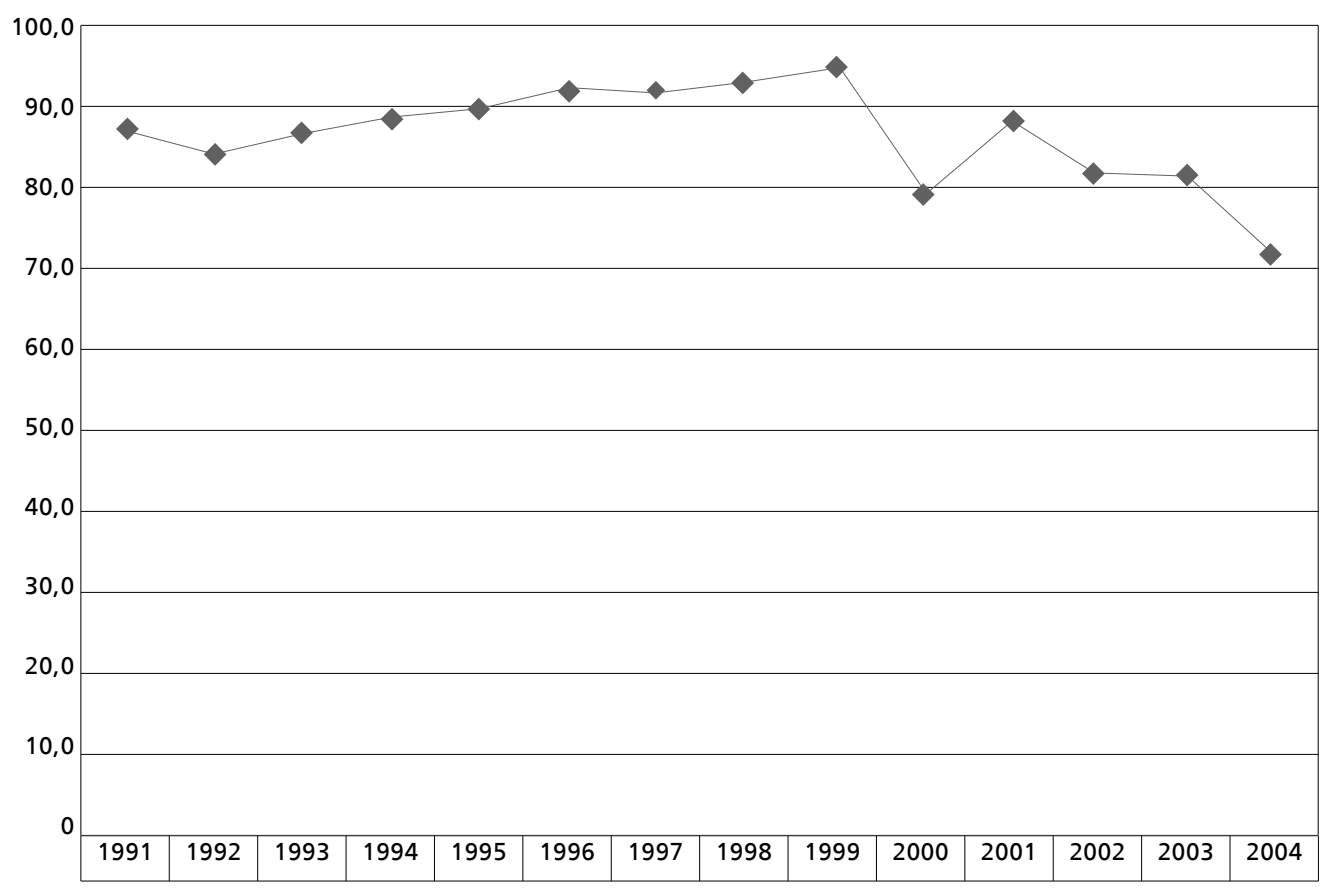

Fonte: Instituto Nacional de Estudos e Pesquisas Educacionais Anísio Teixeira (INEP), Ministério da Educação, Observatório de Recursos Humanos em Saúde (OBSRHS), Instituto de Medicina Social (IMS), Universidade do Estado do Rio de Janeiro.

$51,4 \%$ das vagas ofertadas estavam no setor público de ensino. Já em 1994, o setor público, apesar de deter o maior número de escolas, oferece $41,9 \%$ das vagas. Em 1999, 68,8\% das vagas oferecidas são de instituições privadas. Ressalte-se ainda que esse crescimento não foi eqüitativamente distribuído pelas regiões do país. A concentração da oferta de vagas se deu nas regiões Sudeste $(62,4 \%)$ e Sul $(16,9 \%)$.

A expansão da oferta de vagas foi acompanhada do aumento da relação candidato/vaga, que na década de 80 era em média de 3,5 por vaga e em 1999 chega a 5,7. Cabe ressaltar que o crescimento da rede educacional privada não se refletiu, na década de 90, de forma equivalente, no número de egressos. Neste período, o setor público foi o que mais diplomou enfermeiros (60,2\% em 1995 e $55,7 \%$ em 1999). O reflexo da expansão do número de vagas, especialmente do setor privado, seria observado na década seguinte.

O cenário de crescimento do sistema educativo, com expressiva participação do setor privado e concentrado nas regiões Sul e Sudeste, pode estar atrelado à implementação do Sistema Único de Saúde (SUS), com expansão de postos de trabalho, principalmente na esfera municipal, e à implantação do Programa Saúde da Família (PSF), que se tornou uma perspectiva atraente no mercado de trabalho dos enfermeiros. De forma geral, houve um aumento de postos de trabalho em todo o setor saúde na década de 90 , na qual o patamar de empregabilidade dos enfermeiros atingiu 92,4\% de absorção em 1999.24

A tendência observada na década de 90 se intensifica nos anos 2000. Se, ao final da década de 90, o crescimento de vagas no setor privado foi bastante expressivo, toma proporções muito maiores a partir do ano 2000. O percentual de crescimento de vagas de enfermagem, entre o último ano da década passada e o primeiro desta, foi de $48,2 \%$. Tal crescimento foi de inteira responsabilidade do setor privado de ensino, que teve uma variação percentual de 69,6\%. O número de vagas que, em 2000, girava em torno de 20 mil, chega a 2004 com 70.400 vagas para a graduação de enfermagem. Deste conjunto 
Egressos de graduação de enfermagem segundo natureza administrativa. Brasil, 1991 a 2004.

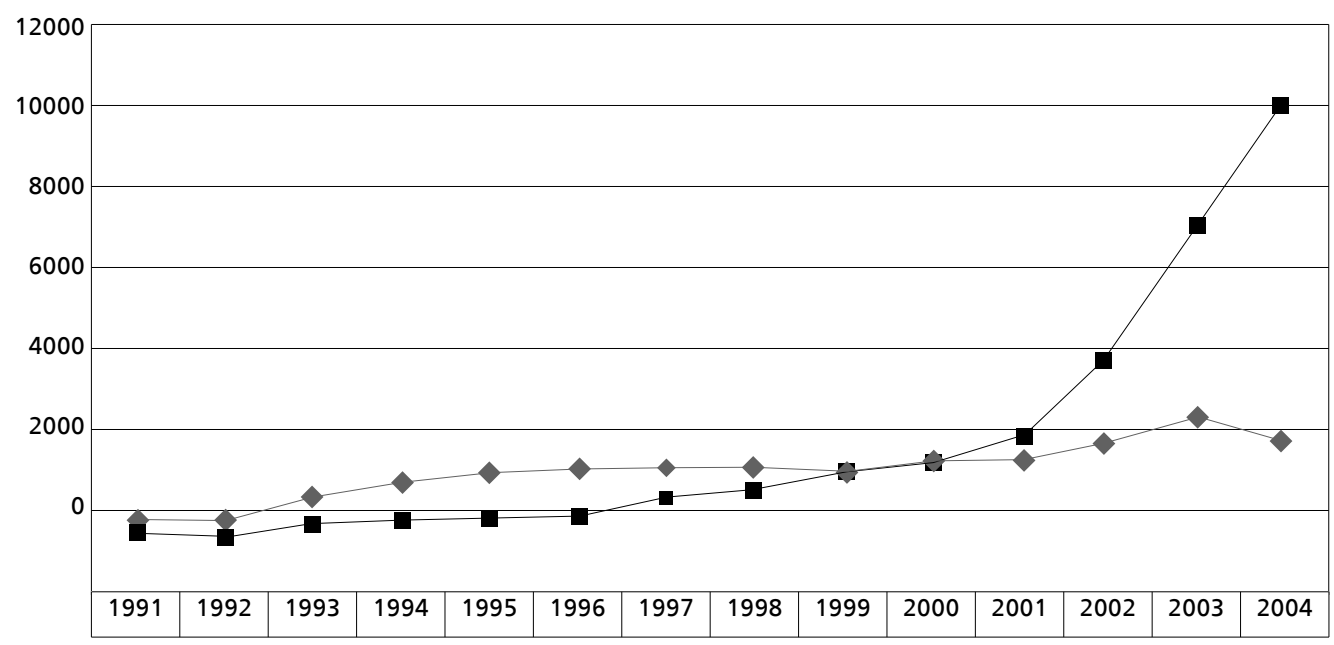

Pública

- Privada

Fonte: Instituto Nacional de Estudos e Pesquisas Educacionais Anísio Teixeira (INEP), Ministério da Educação, Observatório de Recursos Humanos em Saúde (OBSRHS), Instituto de Medicina Social (IMS), Universidade do Estado do Rio de Janeiro.

$92,04 \%$ estão em cursos do setor privado de ensino, e $67,2 \%$ na região Sudeste. Entre o início dos anos 90 e 2004 o crescimento acumulado de vagas de enfermagem foi de $843,7 \%$ (Figura 3 ).

O aumento das vagas foi, obviamente, conseqüência da criação de novos cursos que, em 2004, somam 415 (77,6\% de natureza privada) contra 106 em 1991. O número de cursos da rede pública cresce 4,5\% em 13 anos, e o de número de vagas cresce na ordem de $28,1 \%$ nesse período. Observa-se que, em termos proporcionais, as vagas públicas crescem mais nas regiões Norte (de 190 vagas em 1995 para 536 em 2004) e Nordeste (de 1205 vagas em 1995 para 1925 em 2004).

Apesar do intenso crescimento do número de vagas, é interessante analisar, também, o quantitativo de ingressantes e o percentual de ocupação dessas vagas. Pode-se observar que o percentual de ocupação das vagas se mantém constante por quase todo o período analisado, apresentando uma queda a partir de 2000. Entretanto, comparado ao crescimento do número de vagas, essa queda não é expressiva e mostra que as vagas para a graduação estão sendo preenchidas, de $70 \%$ a $90 \%$, nos quatro últimos anos (Figura 4).

Ao analisarmos as vagas em relação ao tipo de unidade acadêmica, temos que $51,5 \%$ são oferecidas por Universidades, e 28,9\% por Centros Universitários. As demais são por faculdades integradas ou faculdades isoladas.

A mudança observada está na inversão privado/público do quantitativo de diplomados. Enquanto nos anos 90 a rede pública detinha o maior quantitativo de egressos, a partir de 2000 a situação se inverte; a rede privada passa a ostentar o maior o número de egressos. Tal fato já é reflexo da expansão mais acentuada da rede privada a partir de 1997. Observa-se que, em 2004, o percentual de egressos da rede privada chega a $72,1 \%$ (Figura 5).

A tendência ao crescimento de egressos da rede privada provavelmente será mais expressiva, nos anos subseqüentes, em função do boom no número de vagas desse setor e, considerando que o percentual de evasão vem se mantendo entre $23,7 \%$ e $34,5 \%$, terá nos próximos dois anos, considerando uma taxa de evasão de $30 \%$ e calculando os ingressos a partir de 2001, cerca de 99 mil enfermeiros disponíveis no mercado de trabalho. 


\section{Considerações finais}

Diante deste quadro, vale discutir a repercussão para o mercado de trabalho do enfermeiro, nos próximos anos, caso seja mantida a tendência ascendente de ingressantes nos cursos de graduação. Vimos que contaremos nos próximos dois anos, considerando uma taxa de evasão de $30 \%$ e considerando para o cálculo o número de ingressantes a partir do ano de 2001, com cerca de mais 99 mil enfermeiros no mercado de trabalho.

Não se pode dizer que o país não necessita de enfermeiros, haja vista a relação per capita de 0,6 enfermeiros por 1000 habitantes. Dados do Boletim da União Européia 27 mostram contrastes entre os países do Norte daquele continente com os países da Península Ibérica, a Grécia e o Reino Unido. Enquanto os do Norte apresentam relação de mais de 10 enfermeiros para cada 1000 habitantes, nos outros referidos a relação per capita é inferior a cinco por 1000 habitantes. Portugal está envidando esforços para atingir, pelo menos, o patamar de cinco por 1000. Mesmo considerando a enfermagem como um todo, o Brasil ainda se situa abaixo desta marca.

Entretanto, o cenário brasileiro merece ser observado e acompanhado, tanto do ponto de vista quantitativo (pelo impacto do aumento da entrada no mercado de trabalho) quanto do ponto de vista qualitativo (pelo desempenho do pessoal formado). Tais questões vêm exigindo a adoção de medidas regu-

\section{Referências}

1. Teixeira M. Desenhos alternativos de incorporação e gestão do trabalho médico na SMS do Rio de Janeiro: as experiências dos hospitais Lourenço Jorge e Salgado Filho [dissertação mestrado]. Rio de Janeiro: Escola Nacional de Saúde Pública da Fundação Oswaldo Cruz; 1999.

2. Antunes R. Adeus ao trabalho? Ensaio sobre as metamorfoses e a centralidade do mundo do trabalho. São Paulo: Cortez; 2002.

3. Pierantoni C. As reformas do estado, da saúde e recursos humanos: limites e possibilidades. Ciênc Saúde Coletiva. 2001; 6: 341-60.

4. Pochmann M. O emprego na globalização: a nova divisão internacional do trabalho e os caminhos que o Brasil escolheu. São Paulo: Boitempo; 2002.

5. Narasimhan V, Brown H, Pablos-Mendez A, Adams O, Dussault G, Elzinga G, Nordstrom A, Habte D, Jacobs M, Solimano G, Sewankambo N, Wibulpolprasert S, Evans T, Chen L. Responding to the global human resources crisis. Lancet. 2004; 363: 1469-72. [serial Internet] Available from: http:// www.thelancet.com. [2004 maio 1]. latórias para o setor educacional, que visem assegurar a qualidade dos concluintes da graduação de enfermagem.

Foi apresentado, no transcurso deste artigo, o panorama internacional de migração de enfermeiros, revelando como sua ocorrência pode levar à situação crítica um grande número de países em desenvolvimento. O Brasil, pelas barreiras do idioma, ainda não apresenta dados expressivos que indiquem correntes migratórias de enfermeiros. Um estudo realizado por Vieira et al. ${ }^{28}$ aponta que o país tem registro de 513 imigrantes trabalhando na enfermagem. Entretanto, não se tem informações sobre a saída de enfermeiros para outros países. O autor segue apontando que, a continuar o ritmo de expansão da graduação de enfermagem, o Brasil poderá ser referido como um "celeiro" para estes recursos humanos.

Esta perspectiva de inserção no mercado internacional talvez ainda não tenha sido vislumbrada pelos dirigentes de estabelecimentos de ensino superior de enfermagem, sobretudo do segmento privado, que poderiam para agregar atributos a seus cursos, oferecer formas complementares nos currículos, com disciplinas de idiomas estrangeiros, possibilitando a preparação do aluno no transcorrer da graduação, com vista a sua inserção no mercado internacional.

Assim, foi apontada a necessidade de monitoramento do mercado de trabalho no Brasil bem como do fluxo de enfermeiros dentro e fora do país.

6. Martinez J, Martineau T. Human resources in the health sector: an international perspective. Disponível em: http://www.healthsistemsrc.org. [2004 ago 8].

7. Joint Learning Initiative. Human resources for health: overcoming the crisis. Washington, DC; 2005.

8. Buchan J, Kingma M, Lorenzo FM. International migration of nurses: trends and policy implications. Geneva: International Council of Nurses. Avaliable from: http://www.icn.ch/global/Issue5migration.pdf. [2005 apr $8]$.

9. Vieira ALS. Os enfermeiros nos países do Mercosul: estudo comparado da (i)mobilidade profissional no mercado de trabalho em saúde [tese doutorado]. Rio de Janeiro: Escola de Enfermagem Anna Nery da Universidade Federal do Rio de Janeiro; 1998.

10. Abramzón MC. Argentina: situação dos recursos humanos em saúde. In: Organização Pan-americana da Saúde (OPAS). Recursos humanos em saúde no Mercosul. Rio de Janeiro: FIOCRUZ 1995; p. 47-74.

11. Portes A. Los determinantes de la emigración profesional. Rev Parag Sociol. 1997; 14: 23-45. 
12. Vujicic M, Zurn P, Diallo K, Adams O, Dal Poz MR. The role of wages in the migration of health care professionals from developing countries. Human Resourc Health. [Serial on the Internet]. 2004 apr. [cited 2004 aug 12]; 2: [about 14 p.] Available from: http://www.human-resourceshealth.com

13. Commonwealth Secretariat. Code of practice for the international recruitment of health workers: adopted at the PreWHA Meeting of Commonwealth Health Ministers 2003. Geneva. Available from: http://www.thecommonwealth. org/shared_asp_files/uploadedfiles/\{ 7BDD970B-53AE441D-81DB-64C37E992A\}

_CommonwealthCodeofPractice.pdf. [2003 May 18].

14. OEP (Ordem dos Enfermeiros de Portugal). Enfermeiros espanhóis em Portugal: quantos são e quanto tempo por cá ficam? Disponível em: <http://www.enfermeroenportugal .com/ emfermeroenportugal/trabajoportugal/datosordem/ ordem.pdf>. [2005 jul 20].

15. OEP (Ordem dos Enfermeiros de Portugal). Enfermeiros: um panorama crítico a nível mundial. 2005. Disponível em: $<$ http://ordemenfermeiros.pt/index.php?page=44\&highlight=180\# highlight45. [2005 jul 20].

16. OPS (Organización Panamericana de la Salud). Panorama de la fuerza de trabajo em enfermería em América Latina. Washington, DC; 2005. (Serie Desarrollo de Recursos Humanos n. 39).

17. Malvares SM. Panorama de la fuerza de trabajo em enfermería em América Latina. Washington, DC; OPS; 2005. (Serie Desarrollo de Recursos Humanos n. 39)

18. NSW (New South Wales) Health Department. The NSW framework for maternity services. 2000. Available from: http://www.health.nsw.gov.au. [2005 jun 17].

19. NSW (New South Wales) Minister for Health. NSW nursing workforce. Austrália; 2000. Available from: http://www.health.nsw.gov.au>. [2005 jun 17].
20. Vieira ALS, Silva MTN. Pessoal de enfermagem no Brasil e evolução da formação do enfermeiro. Rev Enferm UERJ. 1994; 2: 13-20.

21. Ferraz CA, Nakao JRS, Mishima SM. Dinâmica das graduações em saúde - Enfermagem. In: Vieira Filho A. Dinâmica das graduações em saúde no Brasil: subsídios para uma política de recursos humanos. Brasília, DF: Ministério da Saúde; 2006. p. 65-87.

22. Carvalho AC. Antecedentes históricos. In: Carvalho AC, organizador. Documentário. Brasília, DF: ABEn 1976. p. 319.

23. OBSRHS (Observatório de Recursos Humanos em Saúde), IMS (Instituto de Medicina Social), UFRJ (Universidade do Estado do Rio de Janeiro) 2005. Disponível em http:// www.obsnetims.org.br.

24. Vieira ALS. Empregabilidade dos enfermeiros no Brasil. Rev Enferm UERJ. 2002; 6 (Supl): 65-74.

25. Dal Poz MR, Varella TC. Recursos humanos em saúde no Brasil: políticas e problemas. In: Guimarães R, Tavares RAW, organizadores. Saúde e sociedade no Brasil nos anos 80. Rio de Janeiro: Relume Dumará; 1994. p. 193-207.

26. Mishima SM. Demandas por cursos de enfermagem no estado de São Paulo, Brasil: a década de 80. Rev Panam Salud Publica. 1998; 4: 106-11.

27. Macedo A. Cuidados em saúde: saúde em mapas e números [Editorial]. Bol Inform. (Portugal) 2001; 5: 1-4.

28. Vieira ALS, Garcia CLLM, Silva CA. Imigrantes no Brasil: o caso da enfermagem. In: Anais.VIII Congresso Nacional dos Conselhos de Enfermagem 2005 out 24-28; Maceió, Alagoas. Rio de Janeiro: Conselho Federal de Enfermagem; 2005

Recebido em 22 de janeiro de 2007

Versão final apresentada em 18 de abril de 2007

Aprovado em 24 de abril de 2007 